\title{
DE NUEVO A VUELTAS CON LA ADOPCIÓN SIMPLE EXTRANJERA: COMENTARIO A LA RDGRN DE 16 DE NOVIEMBRE DE $2018\left(30^{\mathrm{a}}\right)^{*}$
}

\author{
RETURNING TO SIMPLE FOREIGN ADOPTION: \\ COMMENTARY ON THE RGDRN \\ OF 16 NOVEMBER 2018 (30TH)*
}

\author{
Ma Jesús SÁnChez CANO \\ Profesora Ayudante Doctora de Derecho Internacional Privado \\ Universidad San Jorge \\ Magistrado Suplente
}

Recibido: 15.03.2020 / Aceptado: 08.04.2020

DOI: https://doi.org/10.20318/cdt.2020.5665

\begin{abstract}
Resumen: Los efectos de una adopción simple extranjera no se agotan en el establecimiento de un vínculo de filiación y en la responsabilidad parental, sino que generan otras consecuencias vinculadas con la filiación adoptiva, como es el régimen del nombre y los apellidos del adoptado en forma simple. Tal es el caso de la RDGRN* ${ }^{* *}\left(30^{a}\right)$ de 16 de Noviembre de $2018^{* * *}$, que analiza la validez en España de una adopción simple francesa en el marco de un expediente de cambio de nombre y apellidos.

Palabras clave: adopción simple, nombre y apellidos, adopción internacional.
\end{abstract}

Abstract: The effects of a simple foreign adoption are not restricted to the establishment of a parental filiation link and parental responsibility, but also generate other consequences associated with the adoptive filiation, such as the regime of the name and surname of the adoptee in simple form. This is the case of the RGDRN (30th) of 16 November 2018, which analyses the validity of a simple French adoption in the context of a file on a change of name and surname.

Keywords: simple adoption, name and surname, international adoption.

Sumario: I. Consideraciones iniciales. II. La eficacia de la adopción simple extranjera en nuestro país. III. El régimen del nombre y los apellidos del adoptado. 1. Examen desde el Derecho español. 2. Análisis desde la perspectiva del Derecho Internacional Privado. III. Estudio de la RDGR de 18 de noviembre de $2016\left(30^{\mathrm{a}}\right)$. 1. Fundamentos de la Resolución. 2. Valoraciones acerca de la Resolución. IV. Conclusiones.

\footnotetext{
"El presente trabajo ha sido elaborado en el marco del Grupo Consolidado de Investigación del Gobierno de Aragón "Ius Familiae", IP Carlos Martínez de Aguirre Aldaz.

${ }^{* *}$ En virtud del art. 2.1.c) del Real Decreto 139/2020, de 28 de enero, por el que se establece la estructura orgánica básica de los departamentos ministeriales (B.O.E. núm. 25, de 29 de enero de 2020), las funciones de la Dirección General de los Registros y del Notariado ha pasado ha desempeñarlas el órgano dependiente del Ministerio de Justicia denominado Dirección General de Seguridad Jurídica y Fe Pública.

*** BMJ Núm.2223, Año LXXIII, Octubre 2019, https://www.mjusticia.gob.es.
} 


\section{Consideraciones iniciales}

1. La RDGRN $\left(30^{\mathrm{a}}\right)$ de 16 de Noviembre de 2018 desestima el recurso interpuesto por un ciudadano español y mayor de edad, adoptado en forma simple en Francia, contra la decisión dictada por la Encargada del Registro Civil de Torremolinos (Málaga) en el marco de un expediente de cambio de nombre y apellidos. La resolución impugnada denegaba el cambio del primer apellido del promotor porque la solicitud se basaba en el reconocimiento previo de una adopción simple constituida ante autoridad extranjera que no resultaba inscribible como tal en el Registro civil español. Ello, debido a que sus efectos no eran equivalentes a los de la adopción regulada en España. No obstante, la Encargada del Registro Civil indicó que la adopción simple constituida ante las autoridades francesas y al amparo de la ley francesa, sí podía ser objeto de una anotación marginal en virtud del artículo $38.3^{\circ} \mathrm{LRC}$.

2. De lo anterior se deduce que los efectos de la adopción simple o no plena extranjera no se agotan en el establecimiento de un vínculo de filiación entre el adoptante o adoptantes y el adoptado en forma simple, ni tampoco en la atribución de la responsabilidad parental a favor de los adoptantes, si el adoptado fuese menor de edad. Ciertamente, no puede desconocerse que de esta institución derivan, además, una serie de consecuencias que presentan conexión con la filiación adoptiva, entre la que se encontraría el régimen del nombre y de los apellidos del adoptado. Surge entonces la duda de si cuestiones como la mencionada quedarán cubiertas por el art.30.2 de la Ley 54/2007 de 28 de diciembre de Adopción Internacional (en adelante, LAI), que establece un sistema de reconocimiento material de la adopción simple extranjera a través de la ley determinada por el art.9.4 Cc, o por el contrario, se gobernarán por la ley designada por la norma de conflicto correspondiente a dicha categoría jurídica, independientemente de que coincida o no con la ley señalada por el art.9.4 Cc.

3. En este punto, hay que matizar que en supuestos como el examinado por la DGRN en su Resolución de 16 de Noviembre del 2018, lo normal es que el reconocimiento de la adopción simple o no plena extranjera se plantee como cuestión previa en el marco de una controversia en la que se formule como cuestión principal un supuesto internacional que tenga por objeto la categoría jurídica mencionada en el párrafo precedente. $\mathrm{O}$ dicho de otro modo, antes de resolver si a un sujeto le pertenece llevar unos determinados apellidos, con carácter previo, deberá verificarse si la adopción simple o no plena puede considerarse válida y existente a dichos efectos.

4. Cabe preguntarse, igualmente, acerca de la incidencia de otras cuestiones que puede suscitar el estudio de la RDGRN de 16 de Noviembre de 2018, tales como la relación del derecho al nombre con el derecho a la vida privada y familiar del art.8 CEDH y la proyección del Derecho de la Unión Europea en esta materia. Todos estos problemas se analizarán a continuación con la finalidad de dar respuesta a los interrogantes que plantea la RDGRN de 16 Noviembre de 2018.

\section{La eficacia de la adopción simple extranjera en nuestro país}

5. En un caso como el que se aborda en este trabajo, el reconocimiento en nuestro país de la adopción simple se presenta como cuestión previa dentro de un expediente de cambio de nombre y apellidos, que aparece como cuestión principal. En este punto, hay que recordar que, a falta de regulación expresa en nuestro sistema de Derecho Internacional Privado, la jurisprudencia mayoritaria española recurre a la teoría de la conexión independiente o de la lex formalis fori, calificando lege fori ambas cuestiones por separado y aplicando a cada una de ellas la norma de conflicto que regula en nuestro ordenamiento la correspondiente categoría jurídica ${ }^{1}$. Ello, a salvo lo previsto en normas específicas

\footnotetext{
${ }^{1}$ Vid. A. Marín López, Derecho Internacional Privado español, I, Parte General, 9a Edición, Granada, 1992, págs.245-250 y A.L. Calvo Caravaca y J. Carrascosa González, Derecho Internacional Privado, Vol.I, Decimoquinta edición, 20014-20015, Granada, Comares, 2014, pp.423-425
} 
que prevean que la cuestión previa se rija por la ley aplicable a la cuestión principal. Aquí, habría que combinar la cuestión previa con la técnica de la sustitución, de tal manera que pudiera suceder que el status filii que se estableciera conforme a la ley determinada conforme a la norma de conflicto aplicable a la cuestión previa no resultase equivalente al status filii resultante en función de la ley reguladora de la cuestión principal, lo que supondría que la adopción simple no desplegaría los efectos propios de la aplicación de la ley reguladora de la cuestión principal².

6. Teniendo en cuenta lo que antecede, para resolver la cuestión previa, primeramente, hay que acudir al art.9.5 Cc., que supedita la eficacia de las adopciones constituidas por autoridades extranjeras a lo previsto en la LAI. De este modo, debe atenderse al art.27 LAI, que regula el control incidental de la validez de la adopción constituida por autoridad extranjera ${ }^{3}$ y que distingue entre las adopciones constituidas conforme al Convenio de La Haya, de 29 de mayo de 1993, relativo a la protección del niño y a la cooperación en materia de adopción internacional (en adelante CH 1993) de aquéllas decretadas por autoridades de países no signatarios de dicho Convenio.

7. Los inconvenientes se suscitan en relación con las adopciones constituidas al margen del $\mathrm{CH}$ 1993, dado que la regularidad de las decretadas con arreglo a la Convención se verifica a través del certificado que acredita que su constitución ha tenido lugar con arreglo al propio Convenio, con el límite del orden público internacional (arts.23 y 24 CH 1993). Respecto de las primeras, el art.27 LAI exige controlar que la adopción reúne los requisitos de reconocimiento de los arts. 5.1.e), 5.1.f) y 26 LAI. De dichos requisitos, a los efectos del presente trabajo, resulta de interés el control que contempla el art.26.2 LAI, en virtud del cual, el Encargado del Registro Civil español deberá corroborar que los efectos de la adopción extranjera se corresponden sustancialmente con los previstos para la adopción en el Derecho español.

8. Tratándose de una adopción simple, resulta obvio que sus efectos de ningún modo pueden equipararse a los de la adopción española, toda vez que, pese a instituir un vínculo de filiación entre el adoptado y los adoptantes, no produce la extinción de los vínculos jurídicos existentes con la familia de origen, contrariamente a lo dispuesto en el art.178.1 Cc. Luego, dado que este tipo de adopciones no cumplen con las exigencias del art.26.2 LAI, su reconocimiento solo puede tener lugar por la vía del art.30 LAI.

9. El art.30 LAI recoge un sistema de reconocimiento material o conflictual, conforme al cual, en nuestro país, los efectos de las resoluciones extranjeras por las que se constituye una adopción simple serán los previstos en la lex causae, determinada conforme al art.9.4 Cc, que, en la actualidad, utiliza como primer punto de conexión el de la residencia habitual del hijo. Ello, sin el recurso a las normas de Derecho procesal civil internacional y con el único límite del orden público internacional español, atendiendo al interés del menor (art.31 LAI), en concordancia con el art.24 CH 19934. Esto significa que la adopción

\footnotetext{
${ }^{2}$ Sobre la técnica de la sustitución, Vid. E. JAYME, "La substitution et le principe d'équivalence en droit international privé", Annuaire de l'Institut de droit international, Session de Santiago, vol. 72, 2007.

${ }^{3} \mathrm{El}$ art.27 LAI incorpora la técnica del reconocimiento incidental, cuyos efectos se circunscriben al procedimiento en el cual la resolución se ha invocado directamente. Vid. A.L. Calvo Caravaca y J. Carrascosa González, Práctica procesal civil internacional (Formularios comentados, textos legales, jurisprudencia y casos prácticos), Granada, Comares, 2001, pp.352 y 353. Sobre el art.27 LAI, Vid. también, J.M. EsPinAR ViCENTE, "Reflexiones sobre algunas de las perplejidades que suscita la nueva regulación de la adopción internacional", Actualidad Civil, № 18, Sección A Fondo, Quincena del 16 al 31 Oct. 2008 , tomo 2, Editorial La Ley 39929/2008, p.7, E. Gómez CAMPelo, "Los perfiles de la competencia judicial internacional en la Ley 54/2007 de adopción internacionall”, REEI, no 18, Diciembre, 2009, p.41, www. reei.org y R. ArenAs García y C. GonZÁLEZ BeILfuss, "La Ley de Adopción internacional: entre la realidad y el deseo" REEI, nº17, junio,2009, p.34., www.reei.org.

${ }^{4} \mathrm{La}$ tesis del reconocimiento material fue acogida por la propia DGRN a partir de la Res. Circular de 15 de julio de 2006 ((BOE-A-2006-15230), en la cual tiene su origen el régimen actual del reconocimiento de las adopciones simples constituidas por autoridades extranjeras. Igualmente, esta teoría fue defendida con anterioridad a la entrada en vigor de la LAI por CALVO CARAVACA y CARRASCOSA GonZÁLEZ, acudiendo al art.9.4 Cc, norma de conflicto aplicable a la filiación natural y adoptiva, de tal manera que sería la ley nacional del adoptado la que determinaría el contenido de los derechos y obligaciones entre el adoptado y la familia adoptante, si bien, estas adopciones simples o no plenas, no tendrían acceso al Registro Civil español ni tampoco conllevarían la adquisición de la nacional española por parte del adoptado. Vid. A.L. CAlvo CARAVACA y J. CARrascosa GonzÁLEz, Derecho Internacional Privado, Vol.II, 7 edición, Granada, Comares, 2006, p.159.
} 
simple o no plena extranjera surtirá efectos en España como tal adopción simple o no plena si se ajusta a la ley designada por el art.9.4 Cc, de la cual también dependerá su validez y existencia. De no ajustarse, como ocurre cuando la ley a la que remite el art.9.4 Cc es la española, la adopción simple no se reconocerá en nuestro país y en consecuencia, no desplegará ninguno de sus efectos, ni resultará posible su conversión en una adopción regulada por el Derecho español. Hay que precisar que el vigente art.9.4. ${ }^{\circ} \mathrm{Cc}$. ha de interpretarse de manera que establece en primer lugar la aplicación de la ley de la residencia habitual del hijo en el momento en que se constituyó la adopción simple por la autoridad extranjera de origen 5 .

10. Los efectos relativos a las relaciones paterno-filiales y particularmente, la atribución de la patria potestad dependerán de lo dispuesto en las normas del Convenio de 19 de octubre de 1996 relativo a la Competencia, la Ley Aplicable, el Reconocimiento, la Ejecución y la Cooperación en materia de Responsabilidad Parental y de Medidas de Protección de los Niños (arts.16 y 17). Este Convenio (en adelante, $\mathrm{CH}$ 1996) resulta aplicable dado su carácter universal y eficacia erga omnes y al mismo se dirige el art.9.4. $2^{\circ} \mathrm{Cc}$ en relación con el art.30.2 LAI. El CH 1996, como regla general, designa la ley de la residencia habitual del menor, al tiempo que introduce normas específicas par solventar el conflicto móvil.

11. Ahora bien, como se ha explicado, los efectos de la adopción simple o no plena no se limitan al establecimiento de un vínculo de filiación y a la atribución de la responsabilidad parental, sino que de esta institución resultan también otros efectos distintos que igualmente presentan vinculación con la filiación adoptiva. En este sentido, se plantea el interrogante de si tales cuestiones entran dentro del ámbito de aplicación del art.30.2 LAI o si por el contrario, dependerán de la ley a la que conduzca la norma de conflicto correspondiente a cada categoría jurídica, independientemente de que coincida o no con la ley determinada por el art.9.4 Cc.

12. Ciertamente, la cuestión no es pacífica y existen posturas doctrinales que defienden una $u$ otra posición. Así, opina un sector doctrinal que será la lex causae, designada por el art.9.4 Cc, la que se aplique a cuestiones conexas, como la obligación de alimentos, los derechos sucesorios o el régimen del nombre y los apellidos ${ }^{6}$. Esta parece ser la interpretación que se infiere del tenor literal del art.30.2 LAI, habida cuenta que, de forma genérica, sujeta los efectos de las adopciones simples o no plenas a la ley determinada conforme al art.9.4 Cc, sin especificar cuáles son esos concretos efectos, a excepción de la atribución de la patria potestad.

13. Otros autores mantienen que la ley reguladora de estos otros efectos jurídicos vendrá determinada por la norma de conflicto aplicable a cada uno de ellos, motivo por el cual es posible que no se corresponda con la ley designada conforme al art.9.4 $\mathrm{Cc}^{7}$. Esta solución parece la más razonable, teniendo en cuenta que es plenamente coincidente con la regla general que, según la doctrina, resulta aplicable a la filiación en supuestos internacionales, sin perjuicio de que los derechos traigan causa de la filiación por naturaleza o de la filiación adoptiva. No cabe, por tanto, establecer distinciones en el caso de la filiación adoptiva en forma simple, máxime, cuando dichas diferencias no operarían para las adopciones simples o no plenas constituidas conforme al CH $1993^{8}$.

\footnotetext{
${ }^{5}$ La cuestión fue abordada por esta misma autora con más detenimiento en M.J. SÁnchez CANO, "Hacia la recuperación de la adopción simple en el Derecho español", Cuadernos de Derecho Transnacional, Octubre 2018), Vol. 10, No 1, pp . 642-675 (DOI: https://doi.org/https://doi.org/10.20318/cdt.2018.4393). En este sentido puede consultarse también, A. DuRÁn AYAGO, Aspectos internacionales de la reforma del sistema de protección de menores. Especial referencia a la adopción internacional", $A E D I P r$, t. XVI, 2016, p.451, así como C. Vaquero López, "Nuevas normas de Derecho internacional privado estatal: una primera aproximación a las reformas legislativas de julio de 2015", Revista Aranzadi Doctrinal num.9/2015, Estudio, Editorial Aranzadi, Cizur Menor, 2015 (BIB 2015\4765 ).

${ }^{6}$ Vid. J.M. Díaz Fraile, "Problemas actuales de la adopción internacional", Anuario de la Facultad de Derecho de la Universidad Autónoma de Madrid, № . 15, 2011 (Ejemplar dedicado a: El menor ante el derecho en el siglo XXI / coord. por Julio Díaz-Maroto y Villarejo, Alma María Rodríguez Guitián), p.138.

7 Vid. A. L. Calvo Caravaca y J. Carrascosa GonzÁlez, La Ley 54/2007, de 28 de diciembre sobre adopción internacional, (Reflexiones y comentarios), Granada, Comares, 2008, pp. 281-286.

${ }^{8}$ Vid., A. L. Calvo Caravaca y J. Carrascosa González “La Ley 54/2007...cit, pp. 271 y 281-286.
} 
14. A mayor abundamiento, esta tesis se encuentra avalada por la interpretación que la doctrina y la jurisprudencia españolas han realizado en torno al problema de la cuestión previa, que, tal como se ha expuesto más arriba, recurre a la calificación lege fori para ambas cuestiones por separado y aplica a cada una de ellas la norma de conflicto que regula en nuestro ordenamiento la correspondiente categoría jurídica.

15. Aún hay otro argumento en el cual encuentra fundamento esta última opinión, en tanto que sería absurdo recurrir a las reglas del CH 1996, en virtud del art.9.4.2 ${ }^{\circ}$, al que remite el art.30.2 LAI, para designar la ley reguladora de otros efectos no cubiertos por el Convenio, que derivan de la filiación adoptiva en su forma simple, tales como los alimentos, los derechos sucesorios o el régimen del nombre y los apellidos, y respecto de los cuales existen normas de conflicto específicas. En concreto y en lo que interesa al presente trabajo, el régimen del nombre y los apellidos del adoptado en forma simple dependerá de las normas del Convenio número 19, de la Comisión Internacional del Estado Civil (CIEC), relativo a la Ley aplicable a los nombres y los apellidos, hecho en Munich el 5 de septiembre de 1980 (en adelante, Convenio de Munich de 1980) ${ }^{9}$.

16. En atención a lo expuesto, es posible concluir que hay efectos jurídicos externos derivados de la filiación por adopción simple o no plena que no se rigen por el art.30.2 LAI, sino por la norma de conflicto que regule la concreta categoría jurídica, que bien puede conducir a una ley distinta a la de determinada conforme al art.9.4 Cc. No obstante lo dicho, recuérdese que si, conforme al art.30.1 LAI, la adopción simple o no plena no se ajusta a la ley designada por el art.9.4 Cc, dicha institución no se reconocerá en nuestro país y tampoco surtirá ninguno de sus efectos.

17. En todo caso, aún superando el reconocimiento material del art.30 LAI, las adopciones simples no podrán ser objeto de inscripción en el Registro Civil Español, pues así lo ordena el apartado 3 del art.30. Tan sólo procederá su anotación registral, por la vía del art.15 en relación con el art.38.3, ambos de la Ley de 8 de junio de 1957, del Registro Civil (art.40.3 Ley 20/2011, de 21 de julio, del Registro Civil. B.O.E. 22 Julio 2011) ${ }^{10}$. La anotación no tiene valor probatorio, sino meramente informativo.

\section{El régimen del nombre y los apellidos del adoptado}

\section{Examen desde el Derecho español}

18. A partir de la reforma efectuada por la Ley $21 / 1987$ nuestro Código Civil no incorpora norma alguna sobre este particular en sede de adopción, en tanto que regula un único tipo de adopción, cuyos efectos se corresponden con los de la filiación por naturaleza ${ }^{11}$. Por este motivo, debe acudirse al art.109 $\mathrm{Cc}$, aplicable tanto a la filiación por naturaleza como a la adoptiva, que a su vez remite a la normativa registral (Ley y Reglamento de Registro Civil), en la cual se establece que, como regla general, el adoptado habrá de llevar los apellidos del adoptante o adoptantes, o en su caso, en los supuestos previstos en el art.178.2 Cc, los del adoptante y su cónyuge o los del adoptante y el otro progenitor, como así dispone el art.201 RRC. Esta solución resulta de todo punto lógica, toda vez que es la filiación la que determina los apellidos, de conformidad con lo previsto en el art.55 LRC, y que solo existe un tipo de filiación.

\footnotetext{
9 Vid. RDGRN (1 ${ }^{\text {a }}$ ) de 30 de octubre de 1996 (RJ 1997\4457). Los alimentos, se regularán por el Protocolo de La Haya, de 23 de noviembre de 2007, sobre la Ley aplicable a las obligaciones alimenticias. ( DOUE núm. 331, de 16 de diciembre de 2009). Los derechos sucesorios quedarán cubiertos por las normas de conflicto del Reglamento (UE) n $\mathrm{n}^{\circ} 650 / 2012$ del Parlamento Europeo y del Consejo, de 4 de julio de 2012, relativo a la competencia, la ley aplicable, el reconocimiento y la ejecución de las resoluciones, a la aceptación y la ejecución de los documentos públicos en materia de sucesiones mortis causa y a la creación de un certificado sucesorio europeo (DOUE núm. 201, de 27 de julio de 2012).

${ }^{10}$ A título ilustrativo, Vid. la Resolución-Circular de 15 de julio de 2006 (B.O.E. 30 Agosto 2006).

${ }^{11}$ Sobre las reformas legislativas del Código Civil en materia de adopción, consúltese: M. GuzMÁn Peces, La adopción internacional. Guía de adoptantes, mediadores y juristas, edición no 1, Editorial La Ley, Madrid, Mayo 2007 y M.A. PéreZ Álvarez, La nueva adopción, Madrid Cívitas, 1989.
} 
19. De otra parte, el art.202 RRC dispone: "Constituida e inscrita una adopción simple, podrá convenirse después en cualquier momento, por escritura pública y en vida del adoptante o adoptantes, la sustitución de los apellidos del adoptado por los de aquél o éstos, o el uso de un apellido de cada procedencia, caso en que se fijará el orden de los mismos." Con todo, la redacción de este precepto es anterior a la reforma del Código Civil de 1987, por la cual se suprimió la adopción simple.

20. Existen algunas excepciones que permiten al adoptado conservar los apellidos que viniera usando previamente a la adopción y que se corresponderían con los de su familia anterior, siempre que se cumplan las condiciones previstas, especialmente, en los arts.204, 205 y 207, por un lado y 209, 210, 217 y 218 RRC, por otro, si bien, como en el caso del art.202, la redacción de todos ellos es anterior a la reforma de 1987.

\section{Análisis desde la perspectiva del Derecho Internacional Privado}

21. Desde el punto de vista conflictual, el nombre y apellidos de la persona física se determina mediante las reglas del Convenio de Munich de 1980 sobre ley aplicable al nombre y apellidos, en vigor en nuestro país y con eficacia erga omnes (art.2). Desplaza, por tanto, al art.9.1 Cc. y al art.219 RRC ${ }^{12}$. El citado Convenio prevé que la ley reguladora del nombre y apellidos de la persona física es su ley nacional, debiendo aplicarse la ley de la nueva nacionalidad en el supuesto de que el sujeto cambie de nacionalidad (art.1), siempre salvo razones de orden público (art.4) y con la excepción de que sea imposible acreditar el Derecho extranjero (art.5). Será también la ley nacional de la persona física la que fijará el cambio de nombre y apellidos ${ }^{13}$.

22. Debe indicarse que el art.1.1. del Convenio de Munich de 1980 dispone que será la ley nacional del sujeto la que regulará las cuestiones previas de las que dependa el nombre y apellidos de una persona física, tales como la adopción. Obsérvese aquí que, a diferencia del art.1 del Convenio, el art.9.4 Cc, al que dirige el art.30 LAI, utiliza como primer punto de conexión el de la residencia habitual del adoptado.

23. El Convenio no contempla cuál es la ley aplicable al nombre y apellidos cuando la persona ostente múltiple nacionalidad, por lo que para determinar dicha ley habrá que acudir, en su caso, a los Convenios internacionales de doble nacionalidad suscritos por España, y en su defecto, al art.9.9 Cc, que declara de aplicación preferente la ley española. Ello, salvo que, como se expondrá, se trate de un sujeto que ostente otra nacionalidad de un Estado miembro de la Unión Europea, además de la española ${ }^{14}$.

24. Por lo demás, no puede desconocerse que el nombre y apellidos de un sujeto se encuentra amparado por el art.8 CEDH y así lo ha entendido el TEDH ${ }^{15}$.

25. Por último, cabe mencionar la incidencia del Derecho de la UE en la aplicación de las normas de conflicto sobre ley aplicable al nombre y apellidos, en concreto, en lo referente al derecho a la

12 Vid. A.L. Calvo Caravaca y J. Carrascosa González, "Tema IX: Persona física” en A.L. Calvo Caravaca y J. CarRascosa González (Dir.), Compendio de Derecho Internacional Privado, Rapid Centro Color S.L., Murcia, 2009, p.250, y M.A. AdAm MuÑoz, "La nueva regulación de la filiación natural en el Derecho internacional privado español", Cuadernos de Derecho Transnacional, (Octubre 2016), Vol. 8, No 2, p.49.

${ }^{13}$ Quedan fuera del ámbito de aplicación del Convenio de Munich las cuestiones estrictamente registrales de la inscripción del nombre y apellidos, tales como la documentación y plazos, que se sujetan a la ley del Estado de la autoridad competente a tal fin. Vid. A.L. Calvo Caravaca y J. Carrascosa González, Derecho Internacional Privado, Vol.I, Decimoquinta edición, 20014-20015, Granada, Comares, 2014, p.51. Puede consultarse igualmente RDGRN num. 45/2016 de 12 febrero 2016 (JUR\2017\133844).

${ }^{14}$ Vid., p.ej., RRDGRN, núm. 2/2002 de 12 febrero (RJ 2002\6180), núm. 1/2005 de 15 marzo (RJ 2005\5484) y núm. 48/2014 de 30 enero (JUR 2014\209353), además de la Instrucción de la DGRN de 23 de mayo de 2007 (JUR\2007\147617).

15 Vid. Sentencia Burghartz vs. Suiza de 22 febrero 1994 [TEDH 1994, 9] y Sentencia Macalin Moxamed Sed Dahir vs. Suiza [no. 12209/10]. 
libre circulación y residencia del art.21 TFUE. Ello, puesto que el cruce de fronteras intra-UE puede comportar la aplicación de una ley distinta, dada la diversidad de las normas de conflicto de los Estados miembros sobre esta materia, y en consecuencia, suponer un obstáculo al citado derecho. La Jurisprudencia del TJUE fundamenta esta cuestión en el principio de reconocimiento mutuo, señalando que la continuidad del nombre y los apellidos de un nacional de un Estado miembro en los demás Estados miembros constituye un tema de validez extraterritorial de decisiones y no de ley aplicable. Por este motivo, ha dejado sentado que el nombre y apellidos legalmente establecido en un Estado miembro ha de ser reconocido en todos los demás Estados miembros, independientemente de lo previsto en las normas de conflicto del Estado de destino y de la ley material designada por estas, con respeto al orden público $\mathrm{y}$ al interés general de dicho Estado ${ }^{16}$.

26. Asimismo, debe indicarse que para la identificación del sujeto que ostenta distintos apellidos y que figuran inscritos en Registros Civiles de Estados diferentes, opera el Convenio de La Haya relativo a la expedición de certificados de diversidad de apellidos, de 8 de septiembre de 1982 (BOE núm. 139, de 10 de junio de 1988).

\section{Estudio de la RDGRN de 18 de noviembre de 2016 (30 $)$}

\section{Fundamentos de la Resolución}

27. La citada Resolución resuelve un recurso formulado contra la decisión de la Encargada del Registro Civil de autorizar el cambio de nombre y denegar el cambio del primer apellido, porque la petición se basa en el reconocimiento previo de una adopción simple constituida ante autoridad extranjera, cuyos efectos no se corresponden con la adopción española y en consecuencia, no susceptible de inscripción en el RCE, sino tan solo de anotación marginal conforme al artículo $38.3^{\circ} \mathrm{LRC}$.

28. El promotor del expediente es un ciudadano español- de origen francés- y residente en nuestro país, que fue adoptado en forma simple por un ciudadano francés ante las autoridades francesas. En su recurso invoca el art $202 \mathrm{RRC}$, que, como ya se ha indicado y reiterará el Centro Directivo, es anterior a la reforma del Código Civil por la Ley 21/1987. Junto a ello, alega el recurrente su interés en que sus apellidos sean iguales en Francia y en España y que, cuando menos, debería practicarse una anotación marginal, con valor meramente informativo, para poner en relación el contenido de los registros español y extranjero. Finalmente, señala que, tratándose de dos Estados miembros de la UE, la sentencia extranjera debe ser reconocida en España sin necesidad de exequátur, desconociendo que no existe ningún instrumento normativo procedente del legislador de la UE que regule esta cuestión ${ }^{17}$.

29. La DGRN deniega la inscripción de la adopción con fundamento en el art.26.2 LAI y resuelve que no procede la modificación de los apellidos del recurrente como consecuencia de la filiación

\footnotetext{
${ }^{16}$ Entre las más destacadas, cabe citar: STJCE 30 marzo 1993, C-168-91, Konstantinidis, STJCE 2 octrube 2003, C-148/02, García Avelló (ECLI:EU:C:2003:539), STJCE 14 octubre 2008, C-353/06, Grunkin-Paul (ECLI:EU:C:2008:559), STJUE 22 diciembre 2010, C-208/09, Wittgestein (ECLI:EU:C:2010:806), STJUE 12 mayo 2011, C-391/09, Vardyn (ECLI:EU:C:2011:291), STJUE 2 junio 2016, C-438/14, Bogendorff (ECLI:EU:C:2016:401) y STJUE 8 junio 2017, C-541/15, Mircea Florian Freitag (ECLI:EU:C:2017:432). En nuestro país, la recepción de esta doctrina jurisprudencial impide una aplicación lineal del art.9.9 Cc y faculta a los nacionales españoles que tengan también otra nacionalidad de otro Estado miembro y cuyo nombre haya sido legalmente establecido en otro Estado miembro, para solicitar que conste de este modo en el RCE. Sin embargo, se aplica el art.9.9 $\mathrm{Cc}$, si se trata de sujetos con doble nacionalidad cuyo nombre ha sido legalmente fijado en primer lugar conforme a la ley española. Vid. de nuevo la Instrucción de la DGRN 23 de mayo de 2007, junto con la Instrucción de la DGRN de 24 de febrero de 2010 (JUR\2010\58561). Pueden consultarse, asimismo, las RRDGRN de 30 mayo 2006 (RJ 2007\3394), de 20 febrero de 2015 (JUR 2015 258167) y 18 noviembre de 2016 (JUR 2018\197400), entre otras. Vid. también, A.L. Calvo Caravaca y J. Carrascosa González, “Tema IX: Persona física” en A.L. Calvo Caravaca y J. Carrascosa González (Dir.), Compendio ...cit, pp.252-258.

${ }^{17}$ En la actualidad y en el ámbito de la UE, tan solo hay una propuesta de Reglamento del Consejo sobre el reconocimiento transfronterizo de resoluciones de adopción (http://www.europarl.europa.eu).
} 
adoptiva Sin embargo, admite que la adopción simple constituida en Francia pueda surtir algunos efectos legales en España, en tanto que genera un vínculo filiación con la nueva familia y en este sentido, indica que si ha sido válidamente constituida en el extranjero, será tratada en España jurídicamente como un acogimiento familiar y podrá ser objeto de "anotación con valor simplemente informativo al amparo de los artículos 38 LRC y 81, 145 y 154.3 RRC”.

30. Seguidamente, el Centro Directivo examina si el cambio solicitado puede ser autorizado a través del mecanismo previsto en el art.207. b) RRC, que permite el cambio de apellidos por los correspondientes a quien tuviera prohijado o acogido de hecho al interesado siempre que aquel haya dado su consentimiento. La conclusión alcanzada por la DGRN es nuevamente negativa, dado que el recurrente no pretende sustituir el apellido paterno por el del acogedor, sino unir este a la primera parte del actual suprimiendo la segunda. Y además, tampoco se ha acreditado que el promotor "usa y es conocido por los apellidos que se solicitan" ni "que dicho uso y conocimiento no ha sido provocado a propósito para conseguir la modificación pretendida", como requiere el art. 205 RRC.

31. A la vista de lo anterior, la DGRN acoge la pretensión del recurrente en el sentido de que es posible la anotación marginal en la inscripción de nacimiento, a efectos meramente informativos y para disipar cualquier duda sobre la identidad del sujeto, toda vez que la atribución de un apellido distinto recogida en el registro del país de origen del promotor afecta al estado civil de un español (art.38.3 $3^{\circ}$ LRC).

32. En último término, el Centro Directivo se opone a la aplicación del art.202 RRC, dado que ha perdido su vigencia desde que la Ley 21/1987 suprimiera la figura de la adopción simple y en su virtud, el Código Civil pasara a regular una sola forma de adopción, cuyos efectos se corresponden con los de la adopción plena.

\section{Valoraciones acerca de la Resolución}

32. Vistos los fundamentos de la Resolución estudiada, primeramente, cabe observar que la DGRN, con carácter previo a valorar la oportunidad o no del cambio de nombre solicitado, decide llevar a cabo un reconocimiento incidental de la adopción simple francesa. En este punto, hay que advertir que el Centro Directivo tan solo realiza el control de correspondencia de efectos con la adopción española del art.26.2 LAI, para concluir que la adopción simple francesa no comporta el cambio de nombre y apellidos, al no haber superado dicho control. Ello, sin tomar en consideración en su argumentación que la eficacia en España de la adopción simple extranjera dependerá de lo dispuesto en el art.30 LAI. De este modo, esta institución únicamente podrá surtir efectos en nuestro país si se ajusta a la ley de la residencia habitual del adoptado en el momento de constituirse la adopción (art.30.1 LAI en relación con el art.9.4. ${ }^{\circ} \mathrm{Cc}$ ), siendo igualmente dicha ley la que determinará su validez y existencia (art.30. $2 \mathrm{LAI}$ ).

33. Habida cuenta que el adoptado en forma simple residía en España al tiempo de la adopción, no cabe duda de que la misma no puede desplegar ninguno de sus efectos en nuestro país, incluidos los referentes al régimen del nombre y de los apellidos como consecuencia de la adopción, puesto que no puede ser considerada válida y existente. Sí es posible, como afirma el Centro Directivo su anotación por la vía de los artículos de las normas registrales en las que motiva su decisión.

34. Sin embargo, conviene hacer una matización que no ha sido tenida en cuenta por la DGRN, puesto que, en el caso examinado, no se trata de otorgar eficacia en España a la adopción simple francesa, sino de determinar los efectos de dicha adopción sobre el nombre y apellidos del sujeto promotor. $\mathrm{O}$ lo que es lo mismo, en el supuesto analizado por la DGRN la adopción opera como cuestión previa de la cual se hace depender el nombre y apellidos del promotor del expediente, lo que, habida cuenta los elementos de extranjería presentes en el sujeto- nacional español, residente en España, y de origen francés- y la existencia de un conflicto móvil, plantea la posibilidad de dar entrada al Convenio de Munich de 1980. 
El art.1 del Convenio remite a la ley nacional del sujeto- ley de la nueva nacionalidad, en caso de conflicto móvil- a la cual quedan sujetas las cuestiones previas, a los solos efectos de precisar el nombre y los apellidos de la persona física ${ }^{18}$. Es decir, en el supuesto examinado, la ley española, que, como resuelve la DGRN, aunque por un camino erróneo, no permite fijar el nombre y apellidos de un ciudadano español adoptado en forma simple de ninguna de las formas pretendidas por el promotor del expediente ${ }^{19}$.

35. También parece oportuno puntualizar que el citado Convenio no contiene normas sobre validez extraterritorial de decisiones, sino únicamente normas de conflicto de leyes, motivo por el cual no puede operar para el reconocimiento de la resolución extranjera por la que se atribuyen los apellidos al promotor del expediente ${ }^{20}$.

36. En cuanto a la posibilidad de proceder a la anotación marginal en la inscripción de nacimiento, con valor meramente informativo, para poner en relación el contenido de los registros español y extranjero y despejar las dudas sobre la identidad del sujeto, la conclusión alcanzada por la DGRN parece razonable. Más aún, cuando el sujeto puede solicitar un certificado de diversidad de apellidos, conforme al Convenio de La Haya relativo al certificado de diversidad de apellidos, en vigor tanto en España como en Francia. De este modo, la persona afectada asegurará su identificación. Aquí, hay que dejar constancia de que la solución del Centro Directivo de ningún modo resulta descabellada, dado que, aunque no resulta aplicable a esta situación, coincide con la prevista en el Convenio de Estambul de 4 de septiembre de 1958. Este Convenio prevé que las resoluciones definitivas recaídas en uno de los Estados contratantes sean anotadas al margen de las actas de estado civil de las personas a las cuales concernieren. Ello, aún estableciendo que tales resoluciones serán ejecutivas de pleno derecho en el territorio de cada uno de los Estados contratantes sin necesidad de exequátur y salvo contrariedad con el orden público internacional del Estado requerido. No obstante, ténganse en cuenta, por lo que se explicará con posterioridad, que este Convenio es anterior a la Jurisprudencia del TJUE sobre la libre circulación de ciudadanos de la Unión Europea y el nombre de las personas físicas.

37. Cabría cuestionarse si la Resolución de la DGRN constituye una infracción del art.8 CEDH. La respuesta parece ser negativa, principalmente, por dos razones:

$\left.1^{a}\right)$ En este caso, el nombre y apellidos del sujeto depende de la adopción simple extranjera, figura ésta que no está recogida en el Derecho español. Por este motivo, la decisión de no

\footnotetext{
${ }^{18}$ El texto original y oficial en francés: reza como sigue: "1. Les noms et prénoms d'une personne sont déterminés par la loi de l'État dont elle est ressortissante. A ce seul effet, les situations dont dépendent les noms et prénoms sont appréciées selon la loi de cet État".

${ }^{19}$ Muy clarificadora resulta la explicación que dan a este tema autores como Calvo Caravaca y Carrascosa González, al señalar que "sólo para precisar el nombre de la persona física, los efectos que las "cuestiones previas" de las que dependen los nombres y apellidos producen sobre el nombre y apellidos se deben regir por la Ley nacional del sujeto. Así, en el caso de un divorcio, si éste afecta a mujer búlgara, los efectos que dicho divorcio produce sobre su nombre y apellidos se rigen por la Ley búlgara (Ley nacional de la persona) con independencia de la Ley que rige el divorcio (SAP Barcelona 18 diciembre 2013 [divorcio entre cónyuges búlgaros]). La Sent. Cass Italia 13 noviembre 2015 [ex-esposa sueca que solicita mantener el apellido de casada] recordó que en Derecho sueco la ex esposa puede elegir, tras su divorcio, mantener el apellido de casada o volver al apellido de soltera. En dicho caso, el ex marido no aceptó que la ex esposa mantuviera el apellido de casada y argumentó que ello no era posible con arreglo a la Ley que regía el divorcio, que era, in casu, la Ley italiana, Ley del país de residencia de los cónyuges, Ley que no permitía conservar dicho apellido a la mujer en el caso concreto. La Corte di Cassazione italiana indicó, por el contrario, que el derecho al nombre es un derecho de la personalidad y se rige por sus propias normas de conflicto. En esta línea, por aplicación del art. 1.1 in fine del Convenio de Munich, los efectos del divorcio sobre el nombre de la esposa se rigen por la Ley nacional de ésta (Ley sueca), con arreglo a la cual era perfectamente posible conservar el apellido de casada" . Vid. A.L. Calvo Caravaca y J. Carrascosa González, "Tema IX: Persona física” en A.L. Calvo Caravaca y J. Carrascosa GonzÁlez (Dir.), Compendio...cit, p. 250, así como A.L. Calvo Caravaca y J. Carrascosa González, Derecho Internacional Privado, Vol.I, Decimoctava edición, 20018-20019, Granada, Comares, 2014, pp.51 y 52.

${ }^{20}$ Los efectos de las resoluciones judiciales o administrativas extranjeras en materia de nombre y apellidos se regulan en el Convenio de Estambul de 4 de septiembre de 1958, relativo a los cambios de apellidos y de nombres (BOE nú.15, de 18 de enero de 1977), si bien excluye los cambios que resulten de una modificación del estado de las personas.
} 
otorgar el cambio de apellidos, lejos de resultar una injerencia injustificada o arbitraria, derivaría directamente de la legislación española aplicable a la situación, que no admite la atribución de los apellidos en los términos solicitados por el promotor del expediente (art.8.2 CEDH).

$2^{\mathrm{a})}$ El TEDH ha reconocido que, en cualquier caso, "el Estado goza de cierto margen de apreciación", si bien "debe tenerse en cuenta el equilibrio justo a mantener entre los intereses concurrentes de la persona y de la sociedad en su conjunto" (Sentencias Keegan y Pini y otros vs. Rumanía).

38. También sería posible preguntarse aquí si la decisión del Centro Directivo podría vulnerar el derecho a la libre circulación de personas (art.21 TFUE), en las condiciones fijadas por el TJUE, antes examinadas. En este punto, hay que resaltar dos consideraciones previas:

$1^{\text {a)}) ~ E n ~ e l ~ s u p u e s t o ~ e x a m i n a d o ~ p o r ~ l a ~ D G R N ~ l a ~ c o n t r o v e r s i a ~ r a d i c a ~ e n ~ s i ~ c a b e ~ a c c e d e r ~ a l ~ c a m b i o ~}$ de apellidos determinado en otro Estado miembro, como consecuencia de una adopción simple constituida por las autoridades de dicho Estado miembro, cuyos efectos no se corresponden con los previstos para la adopción en nuestro ordenamiento jurídico.

$2^{\text {a }) ~ C o m o ~ s e ~ h a ~ p u e s t o ~ d e ~ r e l i e v e, ~ l a s ~ d u d a s ~ q u e ~ p u d i e r a n ~ s u s c i t a r s e ~ s o b r e ~ l a ~ i d e n t i d a d ~ d e l ~ s u j e t o ~}$ y que pudieran resultar un obstáculo a su libre circulación en la UE podrían despejarse con el certificado de diversidad de apellidos que regula el Convenio de La Haya.

39. Ahora bien, pese a lo anterior, hay que recordar que del análisis de la Jurisprudencia del TJUE y en particular, de los Casos Grunkin-Paul y Wittgestein, antes mencionados, se coligen los siguientes extremos:

$\left.1^{\circ}\right)$ El derecho de todos los ciudadanos de un Estado miembro de la UE a mantener en todos los demás Estados miembros el nombre y apellidos fijados de manera oficial con arreglo a la ley de otro Estado miembro ${ }^{21}$.

$2^{\circ}$ ) Obligar a un ciudadano de la UE a cambiar de nombre y apellidos cada vez que traspasa las fronteras de un Estado miembro a otro constituye un obstáculo injustificado a la libre circulación y residencia de dicho ciudadano en todo el territorio de los Estados miembros, reconocido en el art.21 TFUE (antiguo art.18 TCE).

$3^{\circ}$ ) En virtud del principio de reconocimiento mutuo, cuando el nombre y apellidos que ostenta el sujeto haya sido oficialmente concretado por las autoridades de un Estado miembro, de acuerdo con la ley designada por sus normas de conflicto, ha de ser reconocido por las autoridades de otro Estado miembro, independientemente de la ley sustantiva designada por las normas de conflicto de este último Estado.

$4^{\circ}$ ) Un Estado miembro únicamente puede negarse a reconocer el nombre y apellidos atribuido en otro Estado miembro de la UE si ello resulta manifiestamente contrario a su orden público internacional o si afecta al interés general.

40. A la vista de tales consideraciones, podría alegarse que, en materia de apellidos, el orden público internacional español se basa en dos principios fundamentales: el principio de la duplicidad de apellidos de los españoles y el principio de infungibilidad de líneas ${ }^{22}$. Sin embargo, también es verdad

${ }^{21}$ Aún en los casos en que el sujeto no ostente doble nacionalidad de la Unión Europea. De nuevo, Vid. Instrucción de la DGRN de 24 de febrero de 2010 (JUR\2010\58561).

${ }^{22}$ Esta tesis es acogida por la Instrucción de la DGRN de 23 de mayo de 2007 (JUR 2007\147617). En este punto, conviene precisar que el cambio en el nombre y/o los apellidos puede venir exigido por la aplicación de la ley del Estado de la nueva nacionalidad, en cuyo caso es posible mitigar los inconvenientes que ello pueda suscitar. De este modo, si bien la regla general es que la ley que gobierna los apellidos de un ciudadano extranjero que ha adquirido la nacionalidad española es la ley española, esta persona puede mantener los apellidos determinados con arreglo a la ley nacional anterior, siempre que así lo declare en el acto de adquirirla, o dentro de los dos meses siguientes a la adquisición o a la mayoría de edad, al amparo del art.199 
que el propio Centro Directivo ha admitido excepciones para el principio de duplicidad de apellidos, en aplicación de la doctrina del TJUE. Ello conduce, además, a cuestionar que no pueda excluirse, asimismo, la aplicación del orden público internacional en el supuesto del principio de intangibilidad de líneas, tal como entiende un sector doctrinal ${ }^{23}$.

41. Luego, parece razonable concluir que no hay motivos para entender que el reconocimiento en España de los apellidos del sujeto adoptado en forma simple atente contra ninguno de nuestros valores y principios fundamentales, así como que tampoco concurren razones de interés general. Más aún, cuando no es posible afirmar que la adopción simple constituya una institución extraña a nuestro sistema jurídico. Antes al contrario, se trata de una figura que ha estado tradicionalmente presente en el Derecho positivo español, de tal manera que fue la única institución regulada en el Código Civil desde su aprobación y hasta la entrada en vigor de la Ley de 24 de abril de 1958, por la que se introdujo la figura de la adopción plena, con la que convivió, siendo suprimida por la Ley 21/1987, de 17 de noviembre, de modificación de determinados artículos del Código Civil y de la Ley de Enjuiciamiento Civil en materia de adopción. Por este motivo, es posible que todavía hoy subsistan en España adopciones simples, al amparo de la Disposición Transitoria Segunda de la citad Ley 21/1987, y en las cuales sus apellidos se rigieran por lo previsto en el art.202 RRC, invocado por el apelante.

42. A esto hay que añadir que, hoy en día, la adopción simple continúa coexistiendo con la plena en nuestro país, gracias a los sistemas de reconocimiento previstos en el CH 1993 y en el art.30 LAI para las adopciones internacionales. Junto a ello, no debe olvidarse que, en la actualidad, está en auge una corriente doctrinal que aboga por la recuperación de la institución de la adopción simple, como figura a medio camino entre la adopción plena y otras instituciones menos estables, como el acogimiento familiar, como forma de integración familiar mucho más respetuosa con el interés del adoptado.

\section{Conclusiones}

43. Vistos los antecedentes y fundamentos de la resolución de la DGRN y atendiendo tanto al régimen jurídico de la adopción simple en nuestro país como a la normativa registral, junto con la doctrina y jurisprudencia sobre ambas materias, se pueden deducir las siguientes conclusiones:

44. Primera: El Centro Directivo ha procedido a realizar un reconocimiento incidental de la adopción simple extranjera conforme a lo indicado en el art.27 LAI, verificando el control de correspondencia de efectos con la adopción española (art.26.2 LAI), sin tomar en consideración que lo que el promotor solicitaba no era el reconocimiento de la adopción simple francesa en nuestro país y la subsiguiente modificación de los apellidos conforme a la adopción en su inscripción de nacimiento. Como también obvia la DGRN que, en cualquier caso, la eficacia en nuestro país de la adopción simple extranjera se supedita a lo previsto en el art.30 LAI, cuya remisión al art.9.4 Cc, no tiene necesariamente que conducir a la ley española, sino que, en función de los elementos de extranjería de cada situación, puede designar la ley de un país que sí contemple dicha figura.

45. Segunda: De las alegaciones del promotor, en realidad, parece inferirse que lo que en verdad interesa éste es que los apellidos que figuran en el RCE se ajusten a lo previsto en el Registro Civil

RRC (art.56 LRC 2011). Sin embargo, la declaración deberá ajustarse a lo dispuesto en el art.198 RRC y no podrá vulnerar el orden público internacional español, que en materia de apellidos se basa en los dos principios fundamentales citados en el texto Igualmente, esta persona puede escoger el nombre que tenía de conformidad con su ley nacional anterior como nombre propio, aún en la lengua extranjera, en los términos del art.54 LRC (art.51 LRC 2011). Vid. A.L. Calvo CaravacA y J. Carrascosa González, "Tema IX: Persona física" en A.L. Calvo Caravaca y J. Carrascosa González (Dir.), Compendio...cit, pp.250-251.

${ }^{23}$ En este sentido, cabe remitirse a la Doctrina del Centro Directivo citada en la nota al pie n ${ }^{\circ} 16$. Vid. también A.L. CALvo Caravaca y J. Carrascosa González, Derecho Internacional Privado, Vol.I, Decimoctava edición, 20018-20019, Granada, Comares, 2014, p.56. 
francés, tras su adopción en forma simple, a fin de que no surjan dudas respecto de su identidad. En este sentido, promueve el expediente de cambio de nombre y apellidos, que tiene un procedimiento específico en la normativa registral española. Se trata, por tanto, de determinar si su pretensión es posible, para lo cual habrá que tener en cuenta que se está ante un ciudadano español, de origen francés, adoptado en forma simple por un sujeto extranjero y ante la competente autoridad francesa.

46. Tercera: A la vista de lo expuesto en la anterior conclusión, hay que señalar que la DGRN hierra al no aplicar el Convenio de Munich de 1980, que dirige a la ley nacional de la persona física-en el caso estudiado, la española-para determinar el nombre y apellidos del promotor del expediente del cambio de nombre. Como también se equivoca el Centro Directivo al no haberse percatado de que la adopción simple francesa opera en esta situación como cuestión previa de la que dependen el nombre y apellidos del sujeto. Así, según dispone el Convenio de Munich, la DGRN debió haber aplicado el art.1.1 del Convenio para determinar la ley nacional del promotor $y$ así concretar los efectos que la adopción simple produciría en el nombre y los apellidos de dicho sujeto, independientemente de lo dispuesto en el art.30 LAI. Evidentemente, en el supuesto estudiado, será el Derecho sustantivo español el que determinará si es posible el cambio de nombre y apellidos solicitado como consecuencia de la adopción simple. A este respecto, hay que reiterar que nuestro ordenamiento jurídico únicamente recoge la institución de la adopción plena y en consecuencia, no admite el establecimiento del nombre y apellidos de la manera interesada por el promotor del expediente. A la misma conclusión llega el Centro Directivo, si bien, no lo hace aplicando la normativa de Derecho Internacional Privado reguladora del nombre y apellidos de la persona física.

47. Cuarta: La solución del Centro Directivo, en el sentido de proceder a la anotación registral del nombre y apellidos atribuido por la ley francesa, coincide con la prevista en algún texto internacional, y además, nada obsta para que el sujeto pueda solicitar un certificado de diversidad de apellidos, conforme al Convenio de La Haya relativo al certificado de diversidad de apellidos. Por este motivo, no parece que la Resolución de la DGRN conculque el art.8 CEDH.

48. Quinta: El Centro Directivo desconoce el principio de mutuo reconocimiento de nombres y apellidos en la Unión Europea, reiterado por la doctrina del TJUE, habida cuenta que ha optado por denegar el cambio de nombre y apellidos conforme a lo establecido por las autoridades francesas y de acuerdo con la ley francesa. Ello podría acarrear la no aplicación de la ley española designada por el art.1 del Convenio de Munich, en tanto que no respeta el Derecho de la Unión Europea y muy en especial, el derecho de todos los ciudadanos de la Unión a circular y residir libremente en todo el territorio de los Estados miembros de la Unión Europea, que se ve obstaculizado al no poder el sujeto usar en España los apellidos determinados con arreglo a ley designada por las normas de conflicto francesas. Ello, sin que puedan alegarse motivos de orden público o interés general, en tanto que, por las razones explicadas, pese a no estar recogida actualmente en el Derecho español, la adopción simple no resulta desconocida en nuestro ordenamiento jurídico.

49. Sexta: Independientemente de la anotación en el RCE, en aplicación de la jurisprudencia del TJUE, el sujeto promotor del expediente de cambio de nombre tendría derecho a que se concediese el cambio de sus apellidos y se inscribieran en el RCE tal y como están inscritos en el Registro Civil francés. Ello, aunque la ley aplicable al nombre y apellidos de dicho sujeto sea la española. 